Check for updates

Cite this: RSC Adv., 2017, 7, 56023

Received 1st November 2017

Accepted 4th December 2017

DOI: 10.1039/c7ra12022b

rsc.li/rsc-advances

\section{Investigation of optical absorption and photothermal conversion characteristics of binary $\mathrm{CuO} / \mathrm{ZnO}$ nanofluids}

\begin{abstract}
Junfei Fang ${ }^{\mathrm{ab}}$ and Yimin Xuan (D)*b
This work aimed at studying the optical absorption and photothermal conversion of binary $\mathrm{CuO} / \mathrm{ZnO}$ nanofluids that can be used as catalysts in methanol reforming hydrogen production. A series of different component $\mathrm{CuO} / \mathrm{ZnO}$ composite nanoparticles were prepared via a co-precipitation method, and showed the features of uniform diameter distribution, high crystallinity and single crystal structure. The optical absorption, thermal conductivity and photothermal conversion of the composite oxide nanofluids based on water were investigated. The transmission spectrum tests show that the optical absorption properties of the composite oxide nanofluids are effectively enhanced with the introduction of $\mathrm{ZnO}$ in visible light band. And the thermal conductivity tests indicate that the thermal conductivity of the binary $\mathrm{CuO} / \mathrm{ZnO}$ composite nanofluids is higher than that of the pure $\mathrm{CuO}$. The photothermal conversion results show that, due to the addition of $\mathrm{ZnO}$, the photothermal conversion performance of the $\mathrm{CuO} / \mathrm{ZnO}$ composite nanofluids has been enhanced, and the maximum temperature of the nanofluid reaches about $72.649{ }^{\circ} \mathrm{C}$ with the volume fraction of $0.01 \%$, which possesses the highest photothermal efficiency of $97.35 \%$ at $30{ }^{\circ} \mathrm{C}$ and $34.70 \%$ at $70{ }^{\circ} \mathrm{C}$. This implies a simple approach to enhance photothermal conversion for efficient solar energy utilization.
\end{abstract}

\section{Introduction}

Due to the non-renewability of traditional fossil fuel energy, as well as the more and more serious environmental pollution caused by their combustion, energy and environmental problems have become two important restricting factors to the sustainable development of the world economy. Therefore, the exploration of clean and renewable energy and the improvement of energy utilization have become important development strategies for many developed countries. ${ }^{1}$ In so many energy sources, hydrogen is a clean and efficient renewable energy, although hydrogen does not exist in the atmosphere, it is abundant in various organic fuels. So hydrogen production by the decomposition of organic fuels has become a dream of the energy and environmental science workers. Attractively, methanol has the advantages of relatively mild hydrogen conversion conditions (such as low temperature and pressure), convenient storage, low toxicity and so on, thus it becomes the first choice for the preparing of hydrogen energy. ${ }^{2,3}$ At present there are mainly two kinds of catalysts used in methanol reforming, the copper-based catalyst $^{2,4,5}$ and the noble-metal catalyst., ${ }^{2,6,7}$ Compared with the noble-metal one, the advantages of the

${ }^{a}$ Shaanxi Key Laboratory of Industrial Automation, Shaanxi University of Technology, Hanzhong 723001, China

${ }^{b}$ School of Energy and Power Engineering, Nanjing University of Aeronautics \& Astronautics, Nanjing 210016, China.E-mail:ymxuan@nuaa.edu.cn copper-based catalyst are its low cost, high activity and good selectivity on the ratio of produced $\mathrm{CO}_{2}$ and $\mathrm{H}_{2}$, so copper-based catalyst is widely used in methanol steam reforming technology. ${ }^{\mathbf{8} 9}$ However, the reforming reaction temperature of methanol to hydrogen is as high as $200-300{ }^{\circ} \mathrm{C}$, thus it needs to consume a large amount of external energy. Fascinatingly, due to the simple and extensive source and without any harm to environment, the solar energy is the most ideal heating source used for the methanol reforming. ${ }^{10}$ Therefore, how to efficiently absorb and utilize solar energy has become a focus for many researchers. ${ }^{11-13}$

Photothermal conversion is the simplest way to utilize solar energy by using absorption device to convert absorbed solar energy directly into the heat energy. ${ }^{14-16}$ As for nanofluid formed by the stable dispersion of nanoparticles in base liquid, the capture and absorption ability on the incident light will be enhanced due to the enhancement of light scattering from the nanoparticles and the increment of light path of the photon. ${ }^{17-19}$ Moreover, the direct absorption technology by the nanofluid makes the heat transfer process simplified, the thermal resistance reduced, and is conducive to the uniform distribution of temperature. Therefore, the direct solar absorption technology based on nanofluid as a new type of heat collection method has attracted widespread attention. ${ }^{11,17,20,21}$

As is known to all, copper oxide is a narrow band gap semiconductor with excellent absorption properties in visible light, ${ }^{19,22,23}$ thus it can be expected to have significant 
photothermal conversion properties. For instance, Wang et al. ${ }^{\mathbf{1 9}}$ studied the optical absorption and photothermal conversion properties of the $\mathrm{CuO}$ nanofluid, and the results showed that the nanofluid has high photothermal conversion performance under the $635 \mathrm{~nm}$ visible light irradiation. Lee et al. ${ }^{24}$ investigated the effect of the particle shape and size on thermal conductivity of the $\mathrm{CuO}$ nanofluid, and found that the effective conductivity of the nanofluid had increased with the decrease of the particle size. Due to the limited absorption band by a single component nanofluid, it is difficult to achieve broad spectrum utilization of the solar energy, therefore, it is urgent to develop broad spectrum solar energy utilization technology based on the nanofluid. Chen et al. ${ }^{\mathbf{1 6}}$ designed a two-component nanofluid containing copper oxide (CuO) and antimony doped tin oxide (ATO) nanoparticles, and achieved the broad-band absorption across the visible and near-infrared region. Duan et $a l .{ }^{13}$ studied the optical absorption properties of the $\mathrm{TiO}_{2} / \mathrm{Ag}$ core-shell structure plasmonic nanofluid, and found that under the same conditions the $\mathrm{TiO}_{2} / \mathrm{Ag}$ plasmonic nanofluid exhibited a better photothermal performance. Therefore, by appropriately designing the kind, structure and size of the suspended nanoparticles, the synergistic effects between different nanoparticles can be realized, and the absorption band of the nanofluid will be effectively broadened. $\mathrm{ZnO}$ is a direct band gap semiconductor with high thermal conductivity and good chemical stability. ${ }^{25,26}$ Moreover, as for the nanostructured zinc oxide, there are a large number of disordered crystal structures and crystal defects existed on its surface, thus it can be used as active agent in the catalytic reactions. ${ }^{27,28}$ However, the thermophysical properties of the $\mathrm{ZnO}$ nanofluid have not extensively been investigated. With the introduction of $\mathrm{ZnO}$, the crystal structure and particle size of the oxide nanoparticles should be drastically changed. Thus, the optical absorption performance of the composite nanofluids may be effectively regulated by using the synergistic effects between the binary oxide nanoparticles.

Therefore, this work attempted to study the optical absorption and photothermal conversion performance of the binary $\mathrm{CuO} / \mathrm{ZnO}$ nanofluids based on water. First, a series of pure $\mathrm{CuO}$ and $\mathrm{CuO} / \mathrm{ZnO}$ composite oxide nanoparticles were prepared via co-precipitation method. For the as-prepared samples, experimental measurements on surface morphologies, elemental compositions and crystal structures were conducted by using XRD, SEM, TEM, Raman, etc. Then the optical absorption and thermal conductivity of the composite oxide nanofluids based on water were studied. And the photothermal conversion characteristics of the nanofluids as-prepared were also investigated.

\section{Experiment}

\subsection{Preparation of the nanoparticles}

A series of $\mathrm{CuO} / \mathrm{ZnO}$ composite nanoparticles with different components were prepared by using co-precipitation method., ${ }^{4,29,30}$ The specifics of the process were as follows. First, accurately measured stoichiometric ratios of $0.7: 0.3$ and $0.5: 0.5$ of the $\mathrm{Cu}\left(\mathrm{NO}_{3}\right)_{2}$ and $\mathrm{Zn}\left(\mathrm{NO}_{3}\right)_{2}$ aqueous solutions were respectively prepared, and $\mathrm{Na}_{2} \mathrm{CO}_{3}$ aqueous solution with a concentration of $0.5 \mathrm{M}$ was also prepared simultaneously. Subsequently, the metal nitrates solutions $\mathrm{Cu}\left(\mathrm{NO}_{3}\right)_{2}$ and $\mathrm{Zn}\left(\mathrm{NO}_{3}\right)_{2}$ were uniformly dropped into $\mathrm{Na}_{2} \mathrm{CO}_{3}$ aqueous solution with vigorous stirring, while the $\mathrm{pH}$ value of the mixed solution was adjusted at 9.0, and the temperature was raised to $60{ }^{\circ} \mathrm{C}$. After the reaction media was maintained under stirring for 2 hours at $60{ }^{\circ} \mathrm{C}$, the resulting precipitate was cooled statically to room temperature and aged for 1 hour. Then, the obtained blue greenish solid was washed with deionized water and filtered several times until its $\mathrm{pH}$ value was neutral, and immediately the precipitate was dried in an oven at $80^{\circ} \mathrm{C}$ for 12 hours and then placed in a muffle furnace and calcined at $450{ }^{\circ} \mathrm{C}$ for 4 hours. After it was cooled to ambient temperature, the composite oxide nanoparticles were obtained. In order to comparison, the pure $\mathrm{CuO}$ nanoparticles were also prepared via the same method.

\subsection{Preparation of the nanofluids}

Water was chosen as the base fluid, and the oxides/water nanofluids were prepared as follows. ${ }^{19,31}$ At first, a certain amount of the three different oxide powders were dispersed with $100 \mathrm{~mL}$ deionized water at room temperature, followed by ultrasonically vibration for about $30 \mathrm{~min}$. Then the three different oxide/water nanofluids containing $0.01 \%$ volume fraction of oxide nanoparticles were obtained. The other nanofluids with different volume fractions of the oxides were prepared from the $0.01 \%$ one by diluting with different amounts of deionized water and subsequently dispersing for 30 min using ultrasound, in which the volume fractions of the oxide powers were set at $0.005 \%, 0.002 \%, 0.001 \%$ and $0.0005 \%$, respectively. During the experiment, a large amount of precipitation occurs after about 5 hours in the nanofluids with the $0.01 \%$ volume fraction in a static state. However, the precipitation will be dispersed again even if there is slight disturbance.

\subsection{Characterization of the nanoparticles and the nanofluids}

The power X-ray diffraction (XRD) measurements for the composite oxides were performed on a D8 super speed diffractometer (Bruker AXS, Karlsruhe, Germany). The surface morphologies and particle sizes of the nanoparticles were characterized by using S-4800 field-emission scanning electron microscope (SEM) (Hitachi, Tokyo, Japan) with an acceleration voltage of $15 \mathrm{kV}$ and CM100 transmission electron microscope (TEM) (Philips Corporation, Netherlands). The Raman spectra were recorded using an In Via laser confocal Raman spectroscopy (Renishaw Corporation, English) equipped with a $325 \mathrm{~nm}$ diode laser. The diffuse reflection spectra of the oxide powders and the transmittance spectra of the oxide nanofluids based on water were measured with a Cary 500 UV-Vis-NIR spectrophotometer (Varian, USA). The thermal conductivity of the oxide nanofluids was tested by using the TC 3010L thermal conductivity measuring instrument (XiaTech, China). The photothermal conversion properties of the oxide nanofluids with different volume fractions were recorded using a self-built photothermal conversion device. 


\section{Results and discussion}

\subsection{Structure and morphology of the oxide powers}

Fig. 1 shows the $\mathrm{XRD}$ patterns of the as-prepared $\mathrm{CuO}$ and $\mathrm{CuO} /$ $\mathrm{ZnO}$ powers. Curves a, $\mathrm{b}$ and c correspond to the pure $\mathrm{CuO}$ and the $\mathrm{CuO}$ with $\mathrm{ZnO}$ added ratios of $30 \%$ and $50 \%$, respectively. As can be seen from curve a that, a series of obvious diffraction peaks appeared at the $2 \theta$ of $32.47^{\circ}, 35.56^{\circ}, 38.79^{\circ}, 46.22^{\circ}$, $48.90^{\circ}, 53.46^{\circ}, 58.24^{\circ}, 61.55^{\circ}, 66.31^{\circ}, 68.13^{\circ}, 72.52^{\circ}$ and $75.16^{\circ}$. In contrast to the standard XRD patterns for $\mathrm{CuO}$ materials, the diffraction peaks of this product could be indexed to the monoclinic $\mathrm{CuO}$ phase (JCPDS 05-0661). ${ }^{\mathbf{4 5 , 2 9 , 3 2}}$ And no peak from impurities can be observed in the XRD curve of this obtained sample, indicating a high purity of the $\mathrm{CuO}$ product. When the added amount of ZnO is small, such as the introducing amount of $30 \%$ in curve $\mathrm{b}$, the observed diffraction peaks are still mainly attributed to $\mathrm{CuO}$. The peak positions are also exactly the same with the pure $\mathrm{CuO}$, and the crystal structure is still monoclinic phase. However, the diffraction peak has a tendency to broaden and the peak intensity has become weakened, such as at the $2 \theta$ of $35.56^{\circ}$, and it indicates that the crystallinity of the $\mathrm{CuO}$ has been slightly weakened. When the added amount of $\mathrm{ZnO}$ is increased to $50 \%$ in curve c, the diffraction peaks of the $\mathrm{ZnO}$ become stronger and stronger, and the crystal structure of $\mathrm{ZnO}$ is hexagonal phase (JCPDS 361451). ${ }^{5,29,32}$ Due to lattice distortion, the diffraction peaks of $\mathrm{CuO}$ become further weakened, especially for the $\mathrm{ZnO}$ introduced amount of $50 \%$ in curve c. ${ }^{33}$ In addition, there is an interesting phenomenon that a weak diffraction peak appears at the $2 \theta$ of $29.35^{\circ}$ in curve c. In contrast to the standard XRD patterns, we assume that it is attributed to $\mathrm{Cu}_{2} \mathrm{O}$, which is cubic phase (JCPDS 05-0667) ${ }^{34}$ and the reason for the emergence of $\mathrm{Cu}_{2} \mathrm{O}$ may be due to its non-uniform calcination process.

The surface morphologies and particle sizes of the $\mathrm{CuO} / \mathrm{ZnO}$ and $\mathrm{CuO}$ nanoparticles characterized by SEM and TEM are presented in Fig. 2. As can be seen from SEM images in Fig. 2(a) and (c), the morphologies of the $\mathrm{CuO} / \mathrm{ZnO}$ and $\mathrm{CuO}$ particles take on pseudo-spherical shape, and they both exhibit uniform

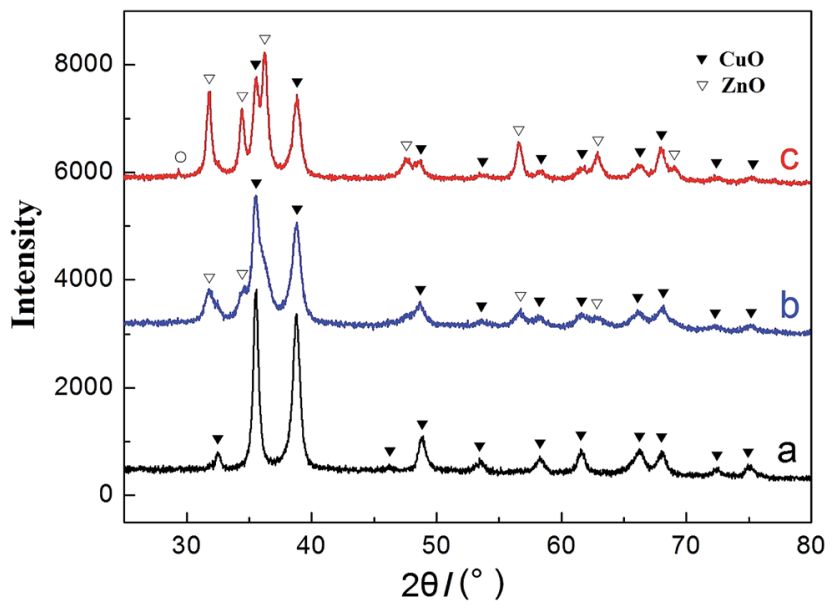

Fig. 1 XRD patterns of the $\mathrm{CuO}$ and $\mathrm{CuO} / \mathrm{ZnO}$ powers (a) pure $\mathrm{CuO}$ : (b) $70 \% \mathrm{CuO}$ and (c) $50 \% \mathrm{CuO}$ size distribution with some compact structures. However, their particle sizes have a little difference, and they are respectively about $30 \mathrm{~nm}$ and $50 \mathrm{~nm}$. Besides, the binary $\mathrm{CuO} / \mathrm{ZnO}$ particle shows looser structure than that of the pure $\mathrm{CuO}$ which can be seen from TEM photographs of the corresponding samples in Fig. 2(b) and (d), respectively. This shows that not only the particle size of the nanoparticles becomes smaller, but also the structure between the agglomerated nanoparticles becomes looser due to the addition of ZnO. Excitedly, both the smaller particle size and loose structure will significantly increase the specific surface area of the samples prepared, and this is very favorable for the occurrence of the optical absorption.

The Raman spectra of the binary $\mathrm{CuO} / \mathrm{ZnO}$ composite nanoparticles are shown in Fig. 3, and curves a and b correspond to the stoichiometric ratios of $0.7: 0.3$ and $0.5: 0.5$, respectively. Previous studies ${ }^{30,34,35}$ have shown that, $\mathrm{CuO}$ with the monoclinic structure has a space group symmetry of $\mathrm{C}_{2 \mathrm{~h}}{ }^{6}$, and there are three zone-center optical-phonon modes of $\mathrm{A}_{\mathrm{g}}$ and $2 \mathrm{~B}_{\mathrm{g}}$ which attribute to the Raman active. That is, there are three peaks of $296 \mathrm{~cm}^{-1}, 346 \mathrm{~cm}^{-1}$ and $636 \mathrm{~cm}^{-1}$ which correspond to the $\mathrm{A}_{\mathrm{g}}, \mathrm{B}_{\mathrm{g}}{ }^{(1)}$ and $\mathrm{B}_{\mathrm{g}}{ }^{(2)}$ modes of the $\mathrm{CuO}$ single crystal, respectively. As can be seen in Fig. 3 that, there are three peaks displayed at about $268.6 \mathrm{~cm}^{-1}, 318.7 \mathrm{~cm}^{-1}$ and $598.4 \mathrm{~cm}^{-1}$ in both the two curves. In comparison with Raman spectra of the $\mathrm{CuO}$ single crystal, the peaks of the Raman active have broadened and occurred downshift. The broadenings and blue shifts of the Raman peaks are mainly attributed to the quantum confinement effect of the $\mathrm{CuO}$ nanoparticles. ${ }^{35}$ Due to the introduction of $\mathrm{ZnO}$, the average diameter of the sample becomes smaller, which can be seen from the SEM images in Fig. 2, thus, it results in the enhancement of the quantum confinement effect. However, there is no other observable peak which refers to $\mathrm{Cu}_{2} \mathrm{O}$ modes, ${ }^{30,36}$ which demonstrates that both the samples prepared have a single phase property.

\subsection{Diffuse reflection property of the oxide powders}

Fig. 4 shows the diffuse reflection spectra of the pure $\mathrm{CuO}$ and binary $\mathrm{CuO} / \mathrm{ZnO}$ oxide powders. The diffuse reflectance curves in Fig. 4(a) were measured with a UV-Vis-NIR spectrophotometer and the corresponding absorbance data in Fig. 4(b) were obtained through the Kubelka-Munk theory. ${ }^{37-39}$ For the solid powder, the relationship between the absorption and diffuse reflection can be described by the Kubelka-Munk function:

$$
A(\lambda)=-\lg [R(\lambda)]
$$

where $R$ is the diffuse reflectance, and $A$ is the absorbance. It can be seen from Fig. 4(a) that, the reflectance of pure $\mathrm{CuO}$ is higher than that of the binary $\mathrm{CuO} / \mathrm{ZnO}$ samples, which indicates that the pure $\mathrm{CuO}$ nanoparticles have higher lightscattering ability than that of the composite samples. ${ }^{40}$ However, the scattering ability of the binary samples is gradually weakened with the increase of $\mathrm{ZnO}$ introducing content. The absorption spectrum of the pure $\mathrm{CuO}$ in Fig. 4(b) exhibits a typical absorption behavior of the narrow band gap semiconductor, and has an absorption edge at about $800 \mathrm{~nm},{ }^{\mathbf{2 2 , 4 1}}$ which corresponds to a band gap of $1.55 \mathrm{eV}$. However, the band 

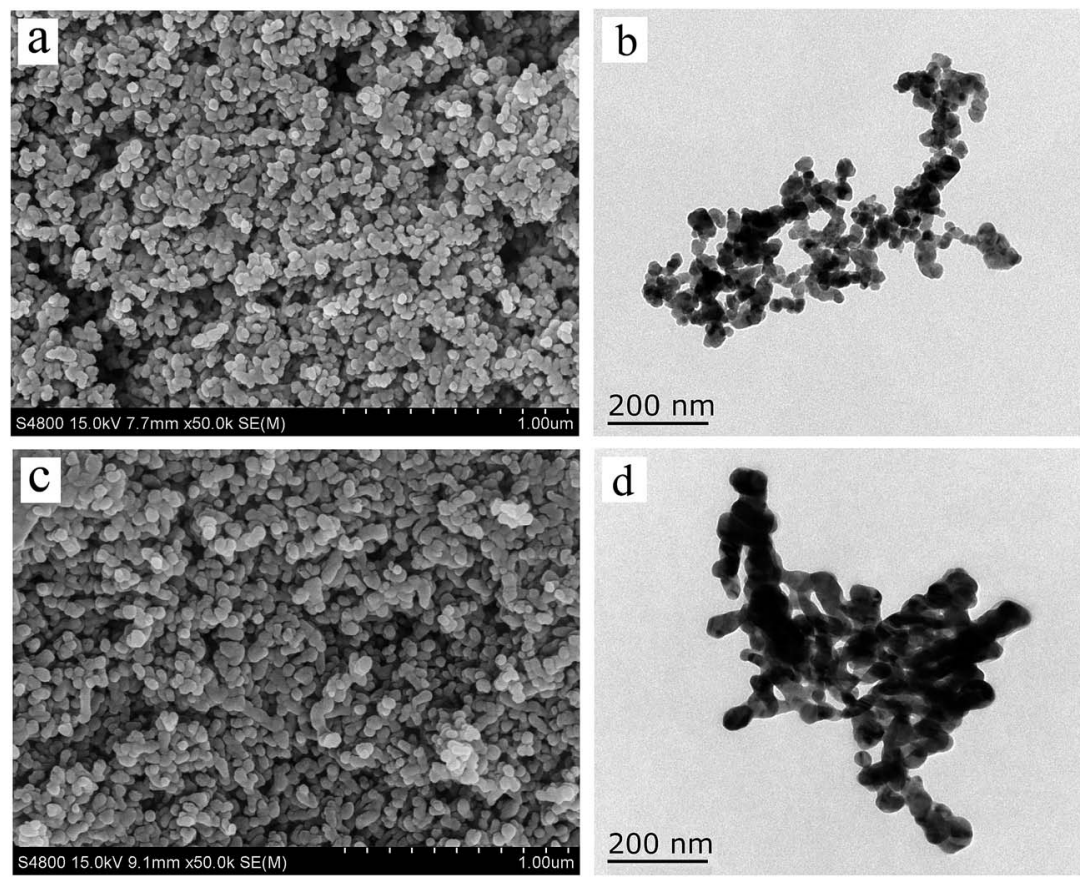

Fig. 2 SEM and TEM images of the nanoparticles ( $a$ and b) $\mathrm{CuO} / \mathrm{ZnO}$ composites; ( $c$ and d) pure CuO.

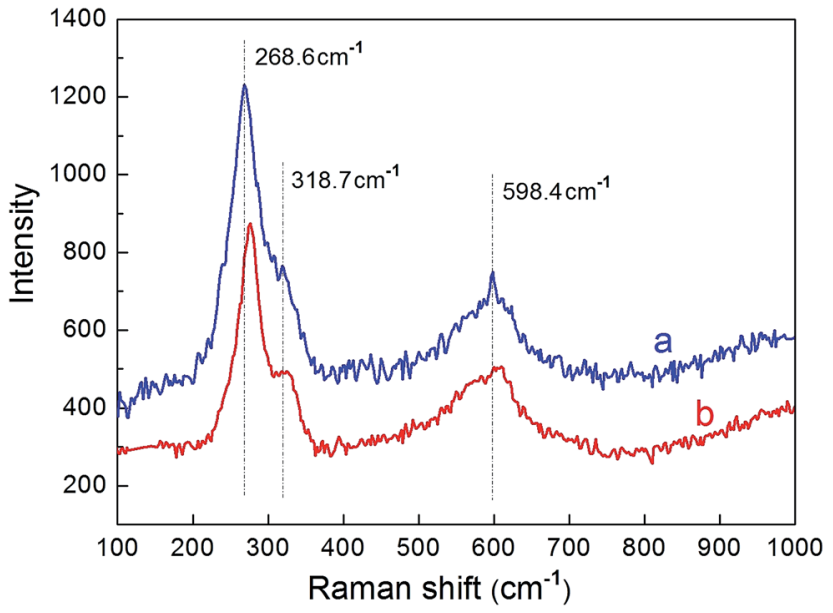

Fig. 3 Raman spectra of the $\mathrm{CuO} / \mathrm{ZnO}$ powers (a) $70 \% \mathrm{CuO}$ and (b) $50 \% \mathrm{CuO}$

gap value is much smaller than the reported one of $1.85 \mathrm{eV}$ for the bulk CuO. ${ }^{42}$ This should be attributed to the quantum size effect because of the so small particle size of the as-prepared $\mathrm{CuO}$ nanoparticles. ${ }^{22}$ Attractively, due to the introduction of $\mathrm{ZnO}$, the optical absorption properties of the composite samples are effectively enhanced, which is in agreement with the earlier study. ${ }^{\mathbf{4 3}}$ The optical properties of nanostructures strongly depend on the absorbance of the material related to the transition of charges from the valence band to the conduction band. ${ }^{43}$ Obviously, the $\mathrm{ZnO}$ introduced can significantly enhance the absorbance, which is caused by the improvement of carrier mobility because of the lattice distortion and impurity levels. ${ }^{44}$ Thus the absorption properties of the composite oxide powers have been enhanced compared with the pure $\mathrm{CuO}$. Moreover, the enhancement becomes larger with the increase of $\mathrm{ZnO}$ introducing content.

\subsection{Optical absorption property of the oxide nanofluids}

The photographs of the pure $\mathrm{CuO}$ and binary $\mathrm{CuO} / \mathrm{ZnO}$ nanofluids based on water with increasing volume fractions of $0.0005 \%, 0.001 \%, 0.002 \%, 0.005 \%$ and $0.01 \%$ are illustrated in Fig. 5. And Fig. 5(a-c) are referred to the pure $\mathrm{CuO}$ and $\mathrm{CuO} / \mathrm{ZnO}$ composites with the component ratios of $0.7: 0.3$ and $0.5: 0.5$, respectively. As can be seen that, the colors of the three nanofluids all deepen gradually with the increase of the volume fractions. At the same time, due to the introduction of $\mathrm{ZnO}$, the transparency of the composite nanofluids with the same volume fraction is becoming more and more apparent, respectively. And this may have an impact on their optical absorption properties.

Fig. 6 shows the transmittance spectra curves of the three different nanofluids corresponded to Fig. 5, respectively, and they are recorded by using the UV/Vis/NIR spectrophotometer with a $10 \mathrm{~mm}$ light path quartz cuvette. For comparison, the spectrum curve of the deionized water was also tested in the experiment. It can be seen from Fig. 6 that, for each nanofluid, all the transmittance decreases sharply as the volume fractions increase, and they are almost down to zero and exhibit total absorption when the volume fractions rise to about $0.01 \%$. There are two marked absorption peaks emerged at the wavelength of about $973 \mathrm{~nm}$ and $1195 \mathrm{~nm}$ in all the spectra curves. And they are attributed to the absorption of water, ${ }^{19,31}$ in which near $973 \mathrm{~nm}$ is the frequency doubling absorption band of the hydroxyl in $\mathrm{H}_{2} \mathrm{O}$ molecular, while near $1195 \mathrm{~nm}$ is that of the 

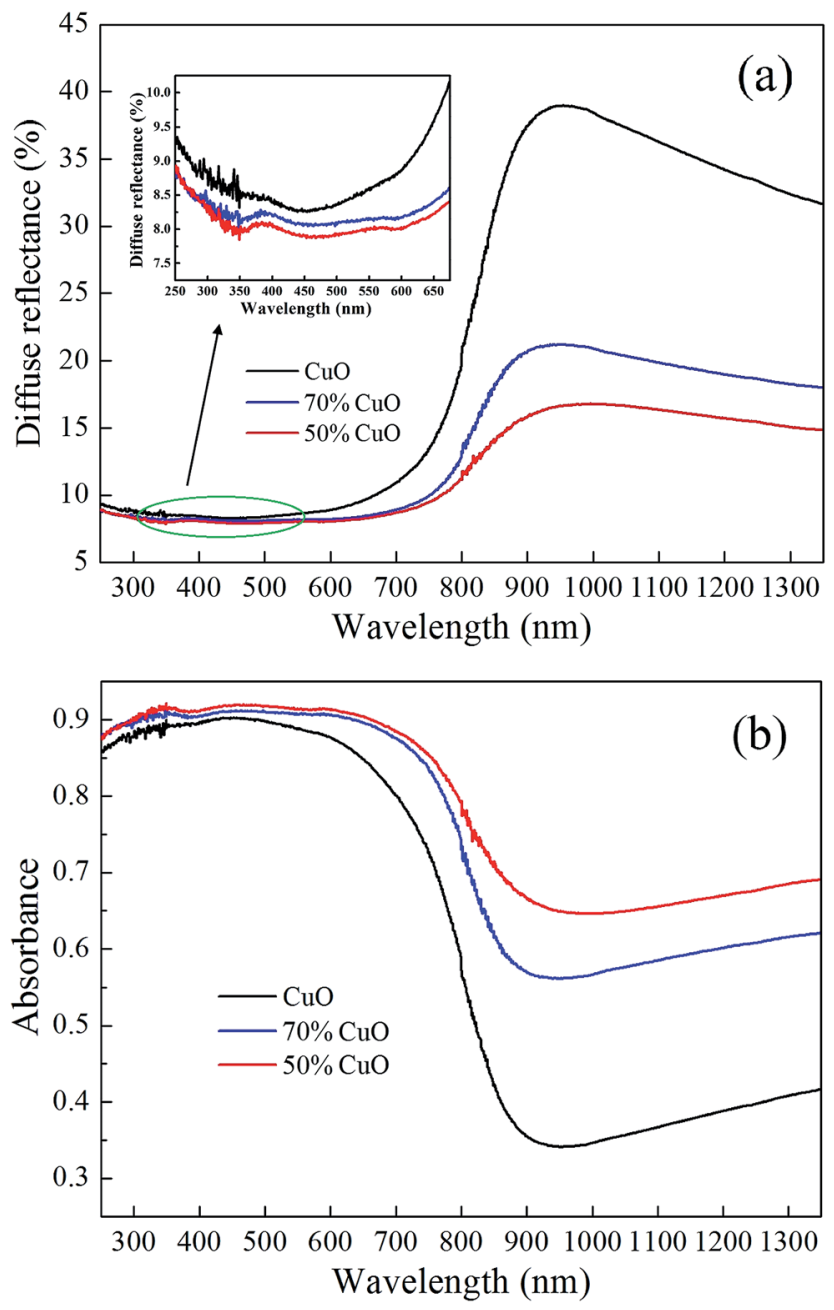

Fig. 4 Diffuse reflection spectra of the $\mathrm{CuO}$ and $\mathrm{CuO} / \mathrm{ZnO}$ powers (a) diffuse reflectance and (b) diffuse reflection absorbance. frequency combination absorption band. Moreover, all the transmittance curves are close to zero at the wavelength greater than $1400 \mathrm{~nm}$, and it is independent of the concentration of the nanofluids. This indicates that the light has been totally absorbed by pure water with the $10 \mathrm{~mm}$ light path. Compared with the pure $\mathrm{CuO}$, the spectra curves of both the composite oxides nanofluids with the same volume fraction have a significant absorption peak at the wavelength about $368 \mathrm{~nm}$, which shows that their absorption properties are enhanced in short wavelength. Moreover, the enhancement becomes larger with the increase of the added content of $\mathrm{ZnO}$.

In water-based nanofluid, the total extinction coefficient of the nanofluid is equal to the sum of the extinction coefficient of base fluid and that of the nanoparticles. ${ }^{17,45}$ So in the experiment of nanofluid absorption with the same base fluid of water, the absorption ability of the nanofluid and the nanoparticles without the influence of base fluid can be evaluated, respectively. According to the Beer-Lambert law, ${ }^{17,31,46}$ in a homogeneous medium, the extinction coefficient $\sigma(\lambda)$ and transmittance $T(\lambda)$ of the nanofluid can be obtained from:

$$
T(\lambda)=1-a(\lambda)=\frac{I}{I_{0}}=\exp [-\sigma(\lambda) L]
$$

where $T(\lambda)$ is the transmittance, $a(\lambda)$ is the absorptance, $\sigma(\lambda)$ is the extinction coefficient, $L$ is the length of the light path, $I$ is the transmitted light intensity and $I_{0}$ is the incident light intensity.

Fig. 7 shows the extinction performance of the three nanofluids with different volume fractions corresponded to Fig. 6, respectively. As can be seen that, the extinction coefficients of the three different nanofluids all increase gradually as the volume fractions increase. Moreover, the extinction coefficients of both the doped oxides nanofluids increase drastically in visible light band, and the enhancement becomes larger with the increase in the introduced content of ZnO. Excitedly, the extinction coefficients increase more than one magnitude, and
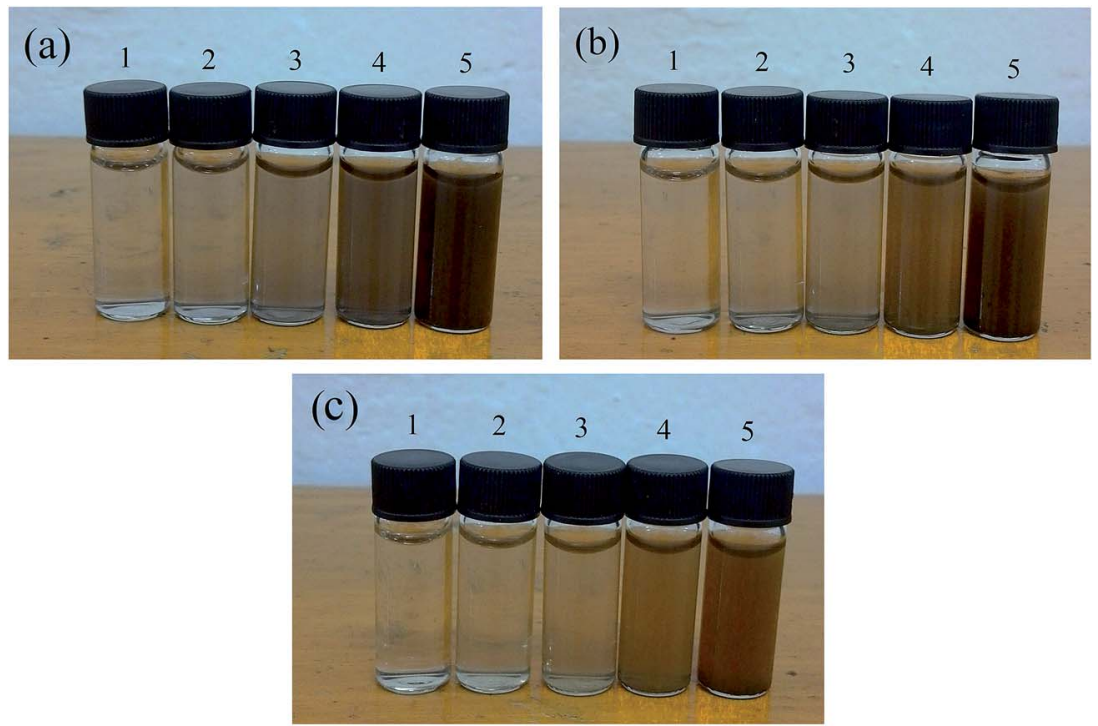

Fig. 5 Photographs of the nanofluids with different volume fractions (a) pure $\mathrm{CuO}$; (b) $70 \% \mathrm{CuO}$ and (c) $50 \% \mathrm{CuO}$. 

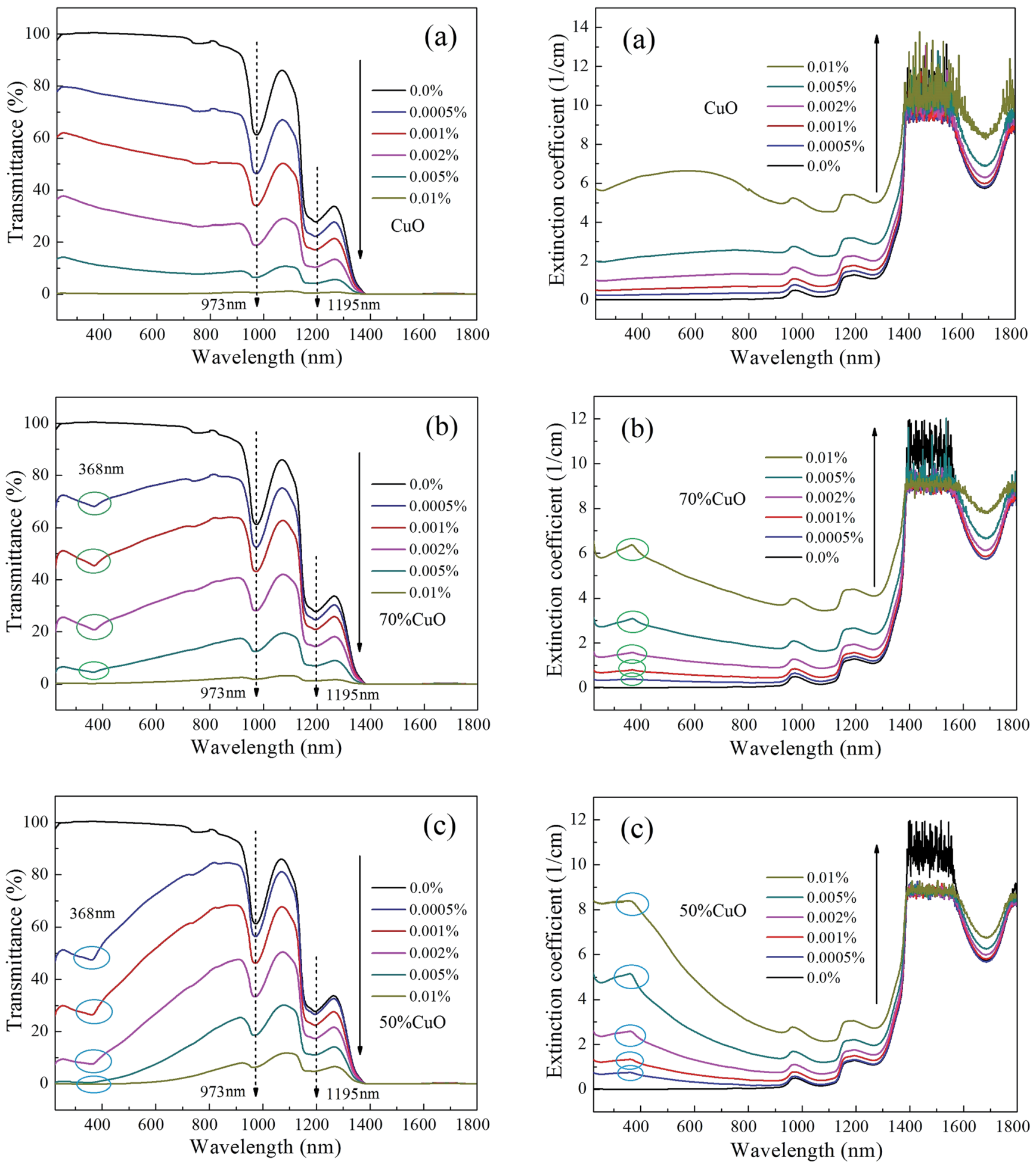

Fig. 6 Transmittance spectra of the nanofluids with different volume fractions (a) pure $\mathrm{CuO}$; (b) $70 \% \mathrm{CuO}$ and (c) $50 \% \mathrm{CuO}$.

reach a maximum when the volume fractions rise to $0.01 \%$, compared with that of the pure water. This indicates that the optical absorption ability has been effectively enhanced due to the addition of the oxide nanoparticles, and only a little amount addition can lead to remarkable improvement on the optical absorption performance.

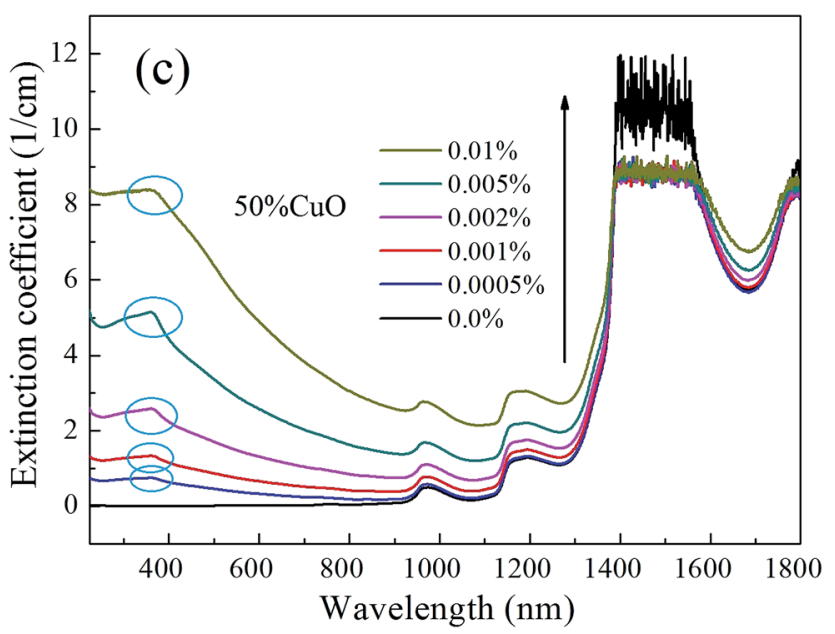

Fig. 7 Extinction coefficients of the nanofluids with different volume fractions (a) pure $\mathrm{CuO}$; (b) $70 \% \mathrm{CuO}$ and (c) $50 \% \mathrm{CuO}$.

By shortening the light path, the transmittance spectra curves of the three different nanofluids with the same volume fraction of $0.01 \%$ at the wavelength range to $2000 \mathrm{~nm}$ were successfully recorded with a $5 \mathrm{~mm}$ thickness quartz cuvette. Simultaneously, the performance of the solar radiation referred 
to the dark cyan curve was also given in the diagram. As can be seen in Fig. 8 that, the transmission intensity at the wavelength range from $200 \mathrm{~nm}$ to $1400 \mathrm{~nm}$ and from $1550 \mathrm{~nm}$ to $1800 \mathrm{~nm}$ increases significantly due to the shortening of the light path in contrast to the transmittance curves in Fig. 6, but complete absorption still appears at the wavelength range from $1400 \mathrm{~nm}$ to $1550 \mathrm{~nm}$ for all the three nanofluids. This further indicates that the absorption of pure water will play a dominant role at the wavelength greater than $1400 \mathrm{~nm}$, while that of the nanoparticles in the nanofluids may be hidden. Besides, the absorption properties of both the composite oxides nanofluids are enhanced in visible light band, for instance, the transmittance curves of the samples with the $\mathrm{ZnO}$ added ratios of $30 \%$ and $50 \%$ are both less than that of the pure $\mathrm{CuO}$ when the wavelength is below $582 \mathrm{~nm}$ and $644 \mathrm{~nm}$, respectively, and they are all larger than $480 \mathrm{~nm}$ referred to the wavelength of the solar radiation maximum intensity. Thus, the absorption performance of the composite oxides nanofluids will be effectively enhanced at the wavelength of the solar radiation maximum intensity. It is well known that $\mathrm{ZnO}$ is a wide band gap semiconductor, ${ }^{47,48}$ and it has excellent optical absorption properties in short wave bands. The optical properties of nanostructures strongly depend on the absorbance of the material related to the transition of charges from the valence band to the conduction band. ${ }^{43}$ Thus it is believed that the optical absorption enhancement in short wave band is caused by the improvement of carrier mobility because of the lattice distortion and impurity levels which is attributed to the introduction of $\mathrm{ZnO}^{\mathbf{4 4 , 4 9}}$ However, on the other hand, the transmittance of composite oxides samples increases gradually in the near infrared-light, and with the increase of the added amount of $\mathrm{ZnO}$, the trend of the increase becomes more and more remarkable.

Therefore, the accurate absorption performance of the three nanofluids should be calculated in order to evaluate their absorption capacity. In our experiment, the transmittance of all the nanofluids can be obtained from Fig. 6 and 8. Thus the percentage of the solar energy absorbed by nanofluids can be represented by the solar weighted absorption fraction $A_{\mathrm{m}}$, which is given by Drotning: ${ }^{46}$

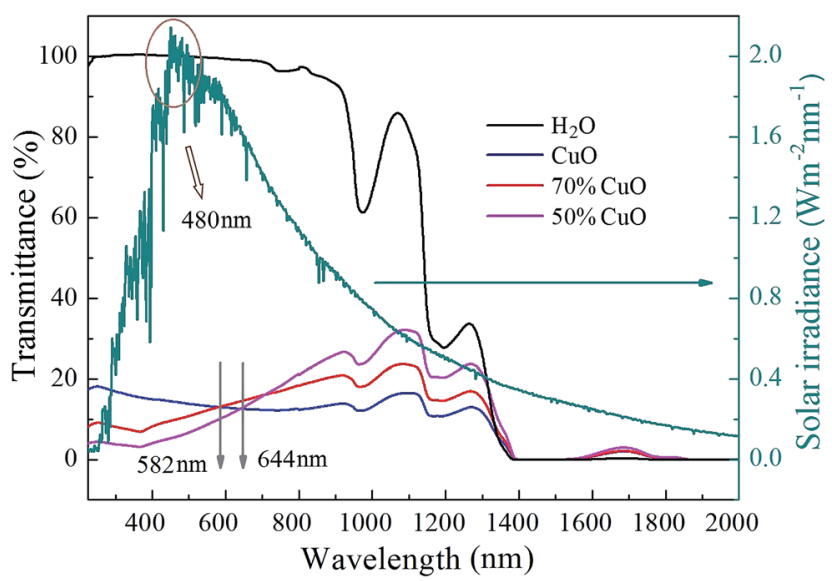

Fig. 8 Transmittance spectra of the nanofluids with the $0.01 \%$ volume fraction.

$$
A_{\mathrm{m}}=\frac{\int_{\lambda_{\min }}^{\lambda_{\max }} I_{\mathrm{AM} 1.5}(\lambda)[1-T(\lambda)] \mathrm{d} \lambda}{\int_{\lambda_{\min }}^{\lambda_{\max }} I_{\mathrm{AM} 1.5}(\lambda) \mathrm{d}(\lambda)}
$$

where $T(\lambda)$ is the transmittance, and $I_{\mathrm{AM} 1.5}$ is the radiation intensity of the AM1.5 solar power spectrum, referring to the ASTMG173. Then the percentages of the solar energy absorbed by the three different nanofluids are obtained, and they are respectively about $88.58 \%, 84.97 \%$ and $79.02 \%$ for the $5 \mathrm{~mm}$ light path. Also, those of the $10 \mathrm{~mm}$ light path with the same volume fraction of $0.01 \%$ are referred to $99.47 \%, 98.67 \%$ and $94.78 \%$, respectively. Obviously, the absorption performance of the pure $\mathrm{CuO}$ is the best, and the absorption ability decreases gradually with the increase of the introduced content of $\mathrm{ZnO}$.

\subsection{Thermal conductivity of the oxide nanofluids}

The thermal conductivity of the three different nanofluids including pure $\mathrm{CuO}$ and $\mathrm{CuO} / \mathrm{ZnO}$ composites with the component ratios of $0.7: 0.3$ and $0.5: 0.5$ with the same volume fraction of $0.01 \%$ is shown in Fig. 9. As can be seen that, the thermal conductivity of all the three different nanofluids increases almost linearly as the temperature increases from $20{ }^{\circ} \mathrm{C}$ to $70{ }^{\circ} \mathrm{C}$. And the thermal conductivity of the binary $\mathrm{CuO} /$ $\mathrm{ZnO}$ composite nanofluids is higher than that of the pure CuO. The reason for the enhancement in the thermal conductivity for the composites nanofluids may be attributed to its smaller size of the nanoparticles. The previous studies ${ }^{24,50}$ showed that the thermal conductivity enhancement of the nanofluid reduces as the particle size increases. In other words, the nanoparticles with smaller size should have higher thermal conductivity in the nanofluids. As shown in Fig. 2, the particle size of the $\mathrm{CuO} /$ $\mathrm{ZnO}$ composite nanoparticles decreases greatly from about $50 \mathrm{~nm}$ to $30 \mathrm{~nm}$ with the introduction of $\mathrm{ZnO}$, and this may lead to a certain increase in heat conduction in the nanofluids. In addition, since the thermal conductivity of the $\mathrm{ZnO}$ is smaller than that of $\mathrm{CuO},{ }^{50,51}$ so the thermal conductivity of the

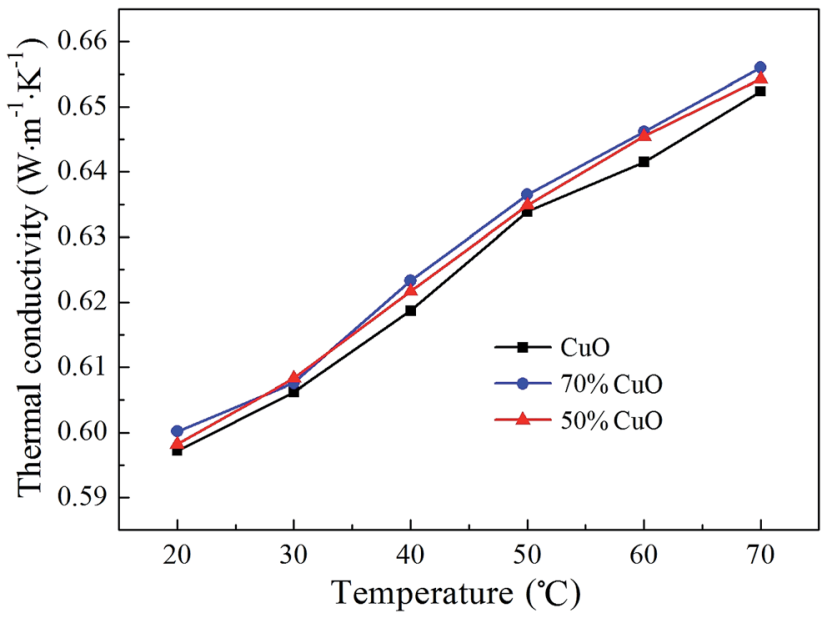

Fig. 9 Thermal conductivity of the nanofluids at different temperatures. 
composites nanofluids decreases with the increase of the introduced content of $\mathrm{ZnO}$.

\subsection{Photothermal conversion property of the oxide nanofluids}

The schematic diagram of the self-built photothermal conversion device is shown in Fig. 10. The light source used in the experiment is the simulated sunlight, and the irradiation intensity is $1000 \mathrm{~W} \mathrm{~m}^{-2}$. The nanofluids are filled in a quartz cuvette, and its size is $12.5 \times 12.5 \times 45 \mathrm{~mm}$. The quartz cuvette is coated with an insulating layer to insulate the energy exchange between the sample cell and the external environment. Simultaneously, the sample cell is connected with a digital thermometer by thermocouple to collect the time and temperature data, then the relationship between the temperature and time will be obtained.

Fig. 11 shows the photothermal conversion curves of the pure $\mathrm{CuO}$ and $\mathrm{CuO} / \mathrm{ZnO}$ composites nanofluids, and the volume fractions of them are all about $0.001 \%, 0.002 \%$, $0.005 \%$ and $0.01 \%$, respectively. And the photographs of the corresponded nanofluids are also illustrated in Fig. 11. In the experiment, the starting temperatures of the three nanofluids were about $26.580{ }^{\circ} \mathrm{C}, 26.577{ }^{\circ} \mathrm{C}$ and $26.535{ }^{\circ} \mathrm{C}$, then the subsequent temperature data were collected at each interval of $10 \mathrm{~s}$. As can be seen from the diagram in Fig. 11, the temperatures of all the three nanofluids with different volume fractions rise continuously under the irradiation. For each nanofluid, the heating rate all increases with the increase of the volume fractions. After a certain period of time, the temperatures of all the nanofluids reach the highest and remain stable. The maximum temperatures of the three nanofluids all appear at the highest volume fraction of $0.01 \%$, and they are respectively about $71.609{ }^{\circ} \mathrm{C}, 72.649{ }^{\circ} \mathrm{C}$ and $71.805{ }^{\circ} \mathrm{C}$, which corresponds to the pure $\mathrm{CuO}$ and $\mathrm{CuO} / \mathrm{ZnO}$ composites with the component ratios of $0.7: 0.3$ and $0.5: 0.5$. And the temperature changes are $45.029^{\circ} \mathrm{C}, 46.072{ }^{\circ} \mathrm{C}$ and $45.270{ }^{\circ} \mathrm{C}$, respectively. Compared to the pure $\mathrm{CuO}$ nanofluid, the temperature increments of the composite oxides both have a certain amount of enhancement, especially for the added amount of $30 \%$, although the enhancement is very small, only about $1{ }^{\circ} \mathrm{C}$. Besides, the maximum temperatures of the three nanofluids at the lowest volume fraction of $0.001 \%$ are about $65.158{ }^{\circ} \mathrm{C}, 66.196{ }^{\circ} \mathrm{C}$ and $66.244{ }^{\circ} \mathrm{C}$,

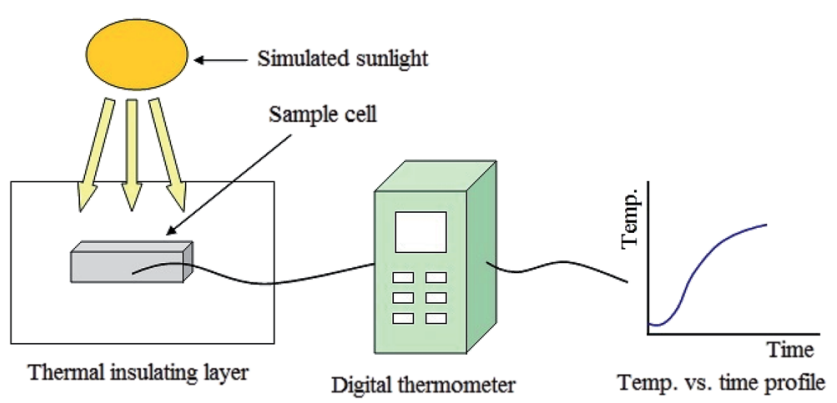

Fig. 10 Schematic diagram of the photothermal conversion device.
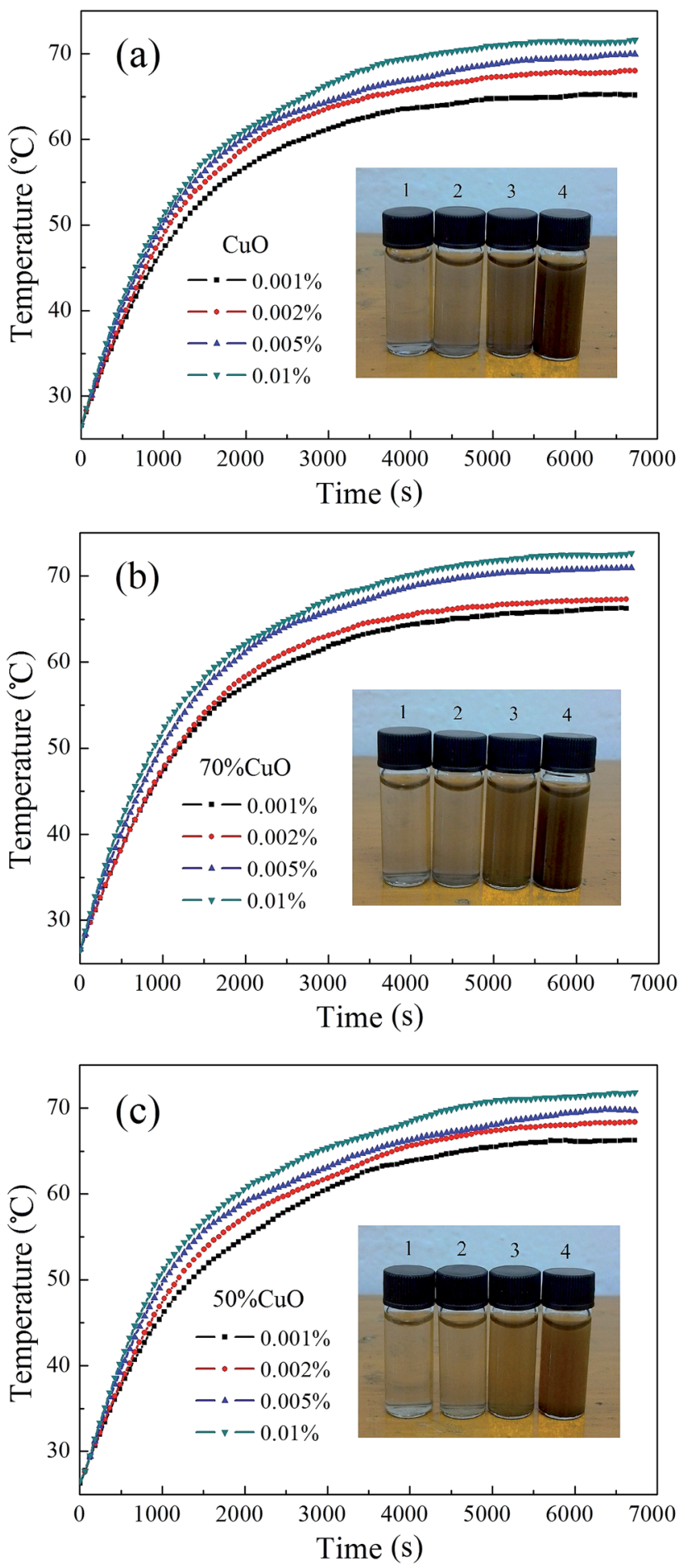

Fig. 11 Photothermal conversion of the nanofluids with different volume fractions (a) pure $\mathrm{CuO}$; (b) $70 \% \mathrm{CuO}$ and (c) $50 \% \mathrm{CuO}$.

respectively. And they are all markedly lower than that of the nanofluids with the volume fraction of $0.01 \%$, which indicates that the concentration of the nanofluids has a great influence on the maximum temperature of the nanofluids. Moreover, with the increase of the volume fraction, the maximum temperatures of the other nanofluids all increase at different extent. 
Furthermore, the photothermal conversion efficiency $\eta$ of the oxides nanofluids can be calculated according to the following formula: ${ }^{13,31}$

$$
\eta=\frac{m c_{\mathrm{p}}\left(T_{\mathrm{s}}-T_{\mathrm{i}}\right)}{A G \Delta t}
$$

where $m$ and $c_{\mathrm{p}}$ are the mass and specific heat of the nanofluid, respectively, $T_{\mathrm{i}}$ is the initial temperature of the nanofluid, $T_{\mathrm{s}}$ is the instantaneous temperature of the nanofluid, $A$ is the top surface area of the sample cell, $G$ is the incident solar heat flux and $\Delta t$ is the time exposed to the solar radiation. In the experiment, the specific heat of the nanofluids is approximately equal to that of the pure water because the concentration of the nanofluids is quite small, and the other parameters can be obtained by experimental test or theoretical calculation. Then the photothermal conversion efficiency of all the three nanofluids at different temperatures was obtained.

The photothermal conversion efficiency curves of the three nanofluids at different temperatures corresponded to Fig. 11 are shown in Fig. 12, respectively. As can be seen that, the maximum of the photothermal efficiency emerges completely at the first acquisition point which corresponds to the temperature of $30^{\circ} \mathrm{C}$ for all the nanofluids, and then the photothermal efficiency decreases gradually as the irradiation time goes on. As for each sample of the nanofluids, the photothermal efficiency increases with the increase of volume fractions from $0.001 \%$ to $0.01 \%$, and the maximum of the conversion efficiency which corresponds to the pure $\mathrm{CuO}$ and $\mathrm{CuO} / \mathrm{ZnO}$ composites with the component ratios of $0.7: 0.3$ and $0.5: 0.5$ are respectively $95.90 \%, 97.35 \%$ and $93.57 \%$ at the volume fraction of $0.01 \%$. Here the $\mathrm{CuO} / \mathrm{ZnO}$ composite with the $\mathrm{ZnO}$ introducing amount of $30 \%$ possesses the highest photothermal efficiency, while that of the $50 \%$ introduced amount shows the lowest photothermal efficiency. In the experiment, the temperature of the nanofluids increases because the radiation energy absorbed by the nanofluids is converted into heat. The thermal characteristics of the nanofluids such as thermal conductivity, specific heat and optical absorption are believed to be the main reasons for the rise of temperature. ${ }^{31}$ As shown in Fig. 9, due to the introduction of $\mathrm{ZnO}$, the thermal conductivity of the binary $\mathrm{CuO} / \mathrm{ZnO}$ composite nanofluids with the volume fraction of $0.01 \%$ is higher than that of the pure $\mathrm{CuO}$, thus it may lead to a certain increase in the heat conduction in the composite nanofluids. On the other hand, the solar weighted absorption fraction of the three nanofluids with the volume fraction of $0.01 \%$ are respectively about $99.47 \%$, $98.67 \%$ and $94.78 \%$. Unfortunately, the optical absorption performance decreases with the increase of the introduced content of ZnO. Therefore, it is believed that there has an optimized amount of $\mathrm{ZnO}$ for the $\mathrm{CuO} / \mathrm{ZnO}$ composite which can make the photothermal conversion efficiency reach the highest. With the temperature increasing, the photothermal efficiency of the nanofluids decreases gradually. When the temperature rises to $70{ }^{\circ} \mathrm{C}$, the photothermal efficiency reduces to the lowest, and they are respectively about $31.72 \%, 34.70 \%$ and $29.92 \%$ for the three nanofluids with the volume fraction of $0.01 \%$. Also, the composite nanofluid with the $\mathrm{ZnO}$ introducing amount of $30 \%$ shows the highest photothermal efficiency.
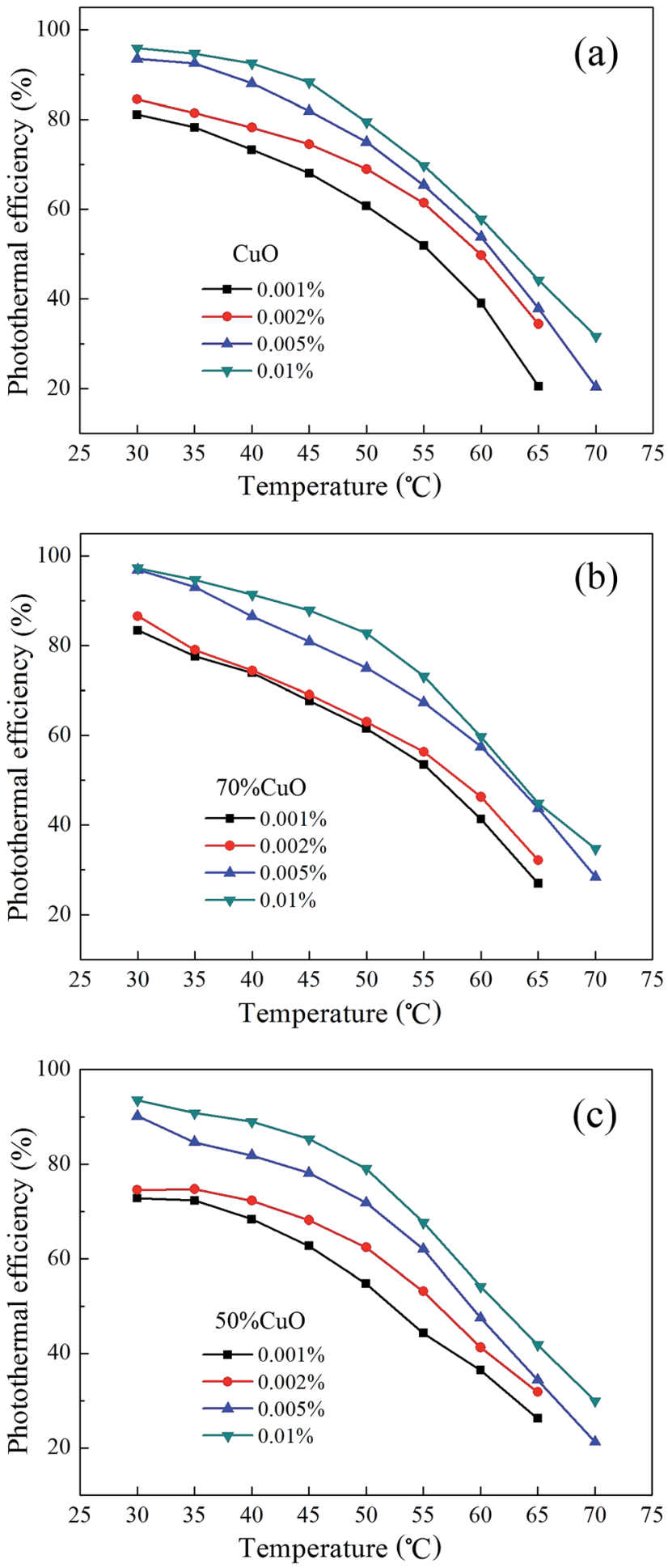

Fig. 12 Photothermal conversion efficiency of the nanofluids at different temperatures (a) pure $\mathrm{CuO}$; (b) $70 \% \mathrm{CuO}$ and (c) $50 \% \mathrm{CuO}$.

\section{Conclusions}

In summary, a series of binary $\mathrm{CuO} / \mathrm{ZnO}$ and pure $\mathrm{CuO}$ nanoparticles were prepared by using a simple co-precipitation method. The experimental measurements on surface morphologies, crystal structures, optical properties and thermal 
conductivity are conducted by using XRD, SEM, TEM, Raman, UV-Vis-NIR spectra, and so on. XRD results show that the crystal structures of the $\mathrm{CuO}$ prepared are all single monoclinic crystal, while those of the ZnO are hexagonal phase. SEM and TEM images illustrate that the size distribution of the as-prepared nanoparticles is very uniform and the particle sizes of the binary $\mathrm{CuO} / \mathrm{ZnO}$ and pure $\mathrm{CuO}$ are about $30 \mathrm{~nm}$ and $50 \mathrm{~nm}$, respectively. Raman spectra also demonstrate that both the composite oxides prepared have a single phase properties, and there is no observable $\mathrm{Cu}_{2} \mathrm{O}$ modes appeared. The transmission spectrum tests show that the optical absorption performance of the composite oxide nanofluids based on water is effectively enhanced with the introduction of $\mathrm{ZnO}$ in visible light band. And the thermal conductivity of the binary $\mathrm{CuO} / \mathrm{ZnO}$ composite nanofluids is higher than that of the nanofluid consisting of pure $\mathrm{CuO}$ nanoparticles at the same volume fraction. The photothermal conversion results show that, compared to the pure $\mathrm{CuO}$, the temperature changes of the $\mathrm{CuO} / \mathrm{ZnO}$ composite oxide nanofluids both have been enhanced, and the maximum temperature of the nanofluid reaches about $72.649{ }^{\circ} \mathrm{C}$ with the volume fraction of $0.01 \%$. Moreover, the $\mathrm{CuO} / \mathrm{ZnO}$ composite nanofluid with the $\mathrm{ZnO}$ introducing amount of $30 \%$ possesses the highest photothermal efficiency, which are $97.35 \%$ at $30{ }^{\circ} \mathrm{C}$ and $34.70 \%$ at $70{ }^{\circ} \mathrm{C}$. This implies a simple approach to enhance the photothermal conversion for the solar energy efficient utilization.

\section{Conflicts of interest}

There are no conflicts to declare.

\section{Acknowledgements}

This work was supported by the National Natural Science Foundation of China (Grant No. 51590901).

\section{References}

1 A. M. Omer, Renewable Sustainable Energy Rev., 2008, 12, 2265-2300.

2 S. Sa, H. Silva, L. Brandao, J. M. Sousa and A. Mendes, Appl. Catal., B, 2010, 99, 43-57.

3 K. Wang, B. Dou, B. Jiang and Y. Xu, Int. J. Hydrogen Energy, 2016, 41, 17334-17347.

4 T. Shishido, Y. Yamamoto, H. Morioka, K. Takaki and K. Takehira, Appl. Catal., A, 2004, 263, 249-253.

5 H. Ajamein and M. Haghighi, Energy Convers. Manage., 2016, 118, 231-242.

6 S. Wang, G. Yang and S. C. Yang, J. Phys. Chem. C, 2015, 119, 27938-27945.

7 L. Oar-Arteta, A. Remiro, F. Epron, N. Bion, A. T. Aguago, J. Bilbao and A. G. Gayubo, Ind. Eng. Chem. Res., 2016, 55, 3546-3555.

8 J. Papavasiliou, G. Avgouropoulos and T. Ioannides, Appl. Catal., B, 2009, 88, 490-496.

9 B. Lindstrom and L. J. Pettersson, Int. J. Hydrogen Energy, 2001, 26, 923-933.
10 J. N. Armor, Catal. Lett., 2005, 101, 131-135.

11 T. P. Otanicar, P. E. Phelan, R. S. Prasher, G. Rosengarten and R. A. Taylor, J. Renewable Sustainable Energy, 2010, 2, 033102.

12 H. Yu, S. Yan, Z. Li, T. Yu and Z. Zou, Int. J. Hydrogen Energy, 2012, 37, 12120-12127.

13 Y. Xuan, H. Duan and Q. Li, RSC Adv., 2014, 4, 16206-16213.

14 M. Abdelrahman, P. Fumeaux and P. Suter, Sol. Energy, 1979, 22, 45-48.

15 M. Faizal, R. Saidur, S. Mekhilef and M. A. Alim, Energy Convers. Manage., 2013, 76, 162-168.

16 N. Chen, H. Ma, Y. Li, J. Cheng, C. Zhang, D. Wu and H. Zhu, Sol. Energy Mater. Sol. Cells, 2017, 162, 83-92.

17 T. A. Robert, P. E. Patrick, T. P. Otanicar, R. Adrian and R. Prasher, Nanoscale Res. Lett., 2011, 6, 225.

18 H. Duan and Y. Xuan, Phys. E, 2011, 43, 1475-1480.

19 L. Wang, M. Wu, D. Wu, C. Zhang, Q. Zhu and H. Zhu, J. Nanosci. Nanotechnol., 2015, 15, 3178-3181.

20 O. Mahian, A. Kianifar, S. A. Kalogirou, I. Pop and S. Wongwises, Int. J. Heat Mass Transfer, 2013, 57, 582-594.

21 B. J. Lee, K. Park, T. Walsh and L. Xu, J. Sol. Energy Eng., 2012, 134, 021009.

22 Y. Wang, D. Meng, X. Liu and F. Li, Cryst. Res. Technol., 2009, 44, 1277-1283.

23 S. Sun, X. Zhang, Y. Sun, S. Yang, X. Song and Z. Yang, Phys. Chem. Chem. Phys., 2013, 15, 10904-10913.

24 S. Lee, S. U. Choi, S. Li and J. A. Eastman, J. Heat Transfer, 1999, 121, 280-289.

25 W. Yu, H. Xie, L. Chen and Y. Li, Thermochim. Acta, 2009, 491, 92-96.

26 M. Kole and T. K. Dey, Thermochim. Acta, 2012, 535, 58-65.

27 M. M. Gunter, T. Ressler, R. E. Jentoft and B. Bems, J. Catal., 2001, 203, 133-149.

28 R. O. Idem and N. N. Bakhshi, Ind. Eng. Chem. Res., 1995, 34, 1548-1557.

29 E. N. Muhamad, R. Irmawati, Y. H. Taufiq-Yap, A. H. Abdullah, B. L. Kniep, F. Girgsdies and T. Ressler, Catal. Today, 2008, 131, 118-124.

30 J. Zhou, Y. Zhang, G. Wu, D. Mao and G. Lu, RSC Adv., 2016, 6, 30176-30183.

31 L. Chen, C. Xu, J. Liu, X. Fang and Z. Zhang, Sol. Energy, 2017, 148, 17-24.

32 C. Mateos-Pedrero, H. Silva, D. A. P. Tanaka, S. Liguori, A. Iulianelli, A. Basile and A. Mendas, Appl. Catal., B, 2015, 174, 67-76.

33 C. Z. Yao, L. C. Wang, Y. M. Liu, G. S. Wu, Y. Cao, W. L. Dai, H. Y. He and K. N. Fan, Appl. Catal., A, 2006, 297, 151-158.

34 T. Yu, X. Zhao, Z. X. Shen, Y. H. Wu and W. H. Su, J. Cryst. Growth, 2004, 268, 590-595.

35 W. Wang, Z. Liu, Y. Liu, C. Xu, C. Zhang and G. Wang, Appl. Phys. A, 2003, 76, 417-420.

36 X. K. Chen, J. C. Irwin and J. P. Franck, Phys. Rev. B, 1995, 52, 13130-13133.

37 L. Li, G. Li, J. Xu, J. Zheng, W. Tong and W. Hu, Phys. Chem. Chem. Phys., 2010, 12, 10857-10864.

38 V. Stengl, S. Bakardjieva and N. Murafa, Mater. Chem. Phys., 2009, 114, 217-226. 
39 Z. C. Orel, M. K. Gunde and B. Orel, Prog. Org. Coat., 1997, 30, 59-66.

40 J. Jiang, F. Gu, W. Shao and C. Li, Ind. Eng. Chem. Res., 2012, 51, 2838-2845.

41 X. Liu, Z. Li, Q. Zhang, F. Li and T. Kong, Mater. Lett., 2012, $72,49-52$.

42 K. Santra, C. K. Sarkar, M. K. Mukherjee and B. Ghosh, Thin Solid Films, 1992, 213, 226-229.

43 S. Sonia, I. J. Annsi, P. S. Kumar, D. Mangalaraj, C. Viswanathan and N. Ponpandian, Mater. Lett., 2015, 144, 127-130.

44 Y. Wang, T. Jiang, D. Meng, D. Wang and M. Yu, Appl. Surf. Sci., 2015, 355, 191-196.
45 M. Du and G. H. Tang, Sol. Energy, 2015, 122, 864-872.

46 W. D. Drotning, Sol. Energy, 1978, 20, 313-319.

47 M. Nafees, W. Liaqut, S. Ali and A. Shafique, Appl. Nanosci., 2013, 3, 49-55.

48 S. Locmelis, C. Brunig, M. Binnewies, A. Borger, K. D. Becker, T. Homann and T. Bredow, J. Mater. Sci., 2007, 42, 19651971.

49 N. M. Basith, J. J. Vijaya, L. J. Kennedy and M. Bououdina, Phys. E, 2013, 53, 193-199.

50 A. T. Baheta and A. D. Woldeyohannes, Asian J. Sci. Res., 2013, 6, 339-345.

51 S. H. Kim, S. R. Choi and D. Kim, J. Heat Transfer, 2007, 129, 298-307. 